Pure Appl. Chem., Vol. 84, No. 7, pp. 1633-1641, 2012.

http://dx.doi.org/10.1351/PAC-CON-11-11-21

(C) 2012 IUPAC, Publication date (Web): 27 May 2012

\title{
Radical azidation reactions and their application in the synthesis of alkaloids*
}

\author{
Guillaume Lapointe, Ajoy Kapat, Karin Weidner, and \\ Philippe Renaud ${ }^{\ddagger}$

\begin{abstract}
Department of Chemistry and Biochemistry, University of Bern, Freiestrasse 3, $\mathrm{CH}-3012$ Bern, Switzerland
\end{abstract}

\begin{abstract}
Recent advances in radical azidation using sulfonyl azides are presented. For instance, radical carboazidation using $\alpha$-iodoketones, desulfitative carboazidation, and antiMarkovnikov hydroazidation of alkenes are described. These novel methods tolerate a large number of functional groups and allow the synthesis of organic azides that would be difficult to synthesize otherwise. The transformation of the azides using reductive processes as well as a Schmidt reaction under nonacidic conditions were used to synthesize alkaloids including indolizidine 167B, monomorine I, cylindricine $\mathrm{C}$, and lepadiformine $\mathrm{C}$.
\end{abstract}

Keywords: alkaloid synthesis; azides; radicals; C-C bond formation; hydroboration; Schmidt reaction.

\section{INTRODUCTION}

Since the preparation of the first organic azide by Peter Grieß in 1864 [1,2], numerous syntheses and applications of these energy-rich molecules have been developed. Azido-containing compounds are highly energetic and yet paradoxically locked up, and this high energy unfolds a huge synthetic versatility ranging from the simple introduction of amino group, to the generation of nitrenes, up to the trigger of rearrangement and cycloaddition reactions [3,4].

The main approach to the synthesis of organic azides involves a classical substitution reaction using an inorganic azide as nucleophile [5]. Tertiary alkyl azides are often difficult to generate via substitution reactions, and free radical processes proved to be particularly efficient for their synthesis [6]. Free radical reactions not only allow the mild introduction of azides, but are also compatible with a large number of functional groups and offer unique possibilities to perform sequential transformations.

Previously, we disclosed an intermolecular radical azidation process that allowed the efficient azidation of secondary and tertiary alkyl radicals using arenesulfonyl azide reagents (Scheme 1) [7-10]. In this reaction, the alkyl radical adds to the $N$-terminal position of the azide moiety to give a 1,3-triazenyl radical [11], which fragments to liberate the corresponding alkyl azide and arenesulfonyl radical. Polar effects are believed to play an important role in this addition. Arylsulfonyl azides are electrophilic radical traps, and only nucleophilic radicals (such as tertiary and secondary carbon-centered radicals) react efficiently with them. The $\alpha$-fragmentation of the arenesulfonyl radical liberating an aryl radical and $\mathrm{SO}_{2}$ is hampered because of the instability of the aryl radical. Therefore, the arenesulfonyl radical can further react and propagate the chain process.

*Pure Appl. Chem. 84, 1543-1667 (2012). A collection of invited papers based on presentations at the $23^{\text {rd }}$ International Conference on Heterocyclic Chemistry (ICHC-23), Glasgow, UK, 31 July-4 August 2011.

¥Corresponding author 


$$
\begin{aligned}
& \mathrm{R} \cdot+\overline{\mathrm{N}}=\stackrel{+}{\mathrm{N}}=\mathrm{N}-\mathrm{SO}_{2} \mathrm{Ar} \longrightarrow \\
& \mathrm{R}^{\prime}-\stackrel{+}{\mathrm{N}}=\mathrm{N}-\mathrm{SO}_{2} \mathrm{Ar} \\
& \stackrel{\mathrm{N}-\dot{\mathrm{N}}=\mathrm{N}}{\mathrm{R}}-\mathrm{SO}_{2} \mathrm{Ar} \longrightarrow \mathrm{R}-\mathrm{N}_{3}+\mathrm{ArSO}_{2} \cdot
\end{aligned}
$$

Scheme 1 Addition of carbon-centered radical onto arylsulfonyl azide.

From the standpoint that sulfonylazides are reactive only toward nucleophilic radicals, the radical azidation could be integrated in an intermolecular process that encompasses the addition of an electrophilic ethoxycarbonylmethyl radical to unactivated alkenes, followed by azidation. This threecomponent sequence represents a formal carboazidation of alkenes (Scheme 2) [12,13]. When followed by a reduction/lactamization sequence, this reaction gives direct access to pyrrolizidinones and indolizidinones. While the first set of conditions developed used hexabutylditin as chain transfer reagent, later on it was found that the use of triethylborane in ethanol/water was equally efficient in achieving this transformation [14]. Alternatively, 3-pyridinesulfonyl azide could be used instead of benzenesulfonyl azide to facilitate the purification of the products [15]. This radical carboazidation was further showcased in the synthesis of lepadiformine $\mathrm{A}[16]$ and (+)-hyacinthacine $\mathrm{A}_{1}$ [17].

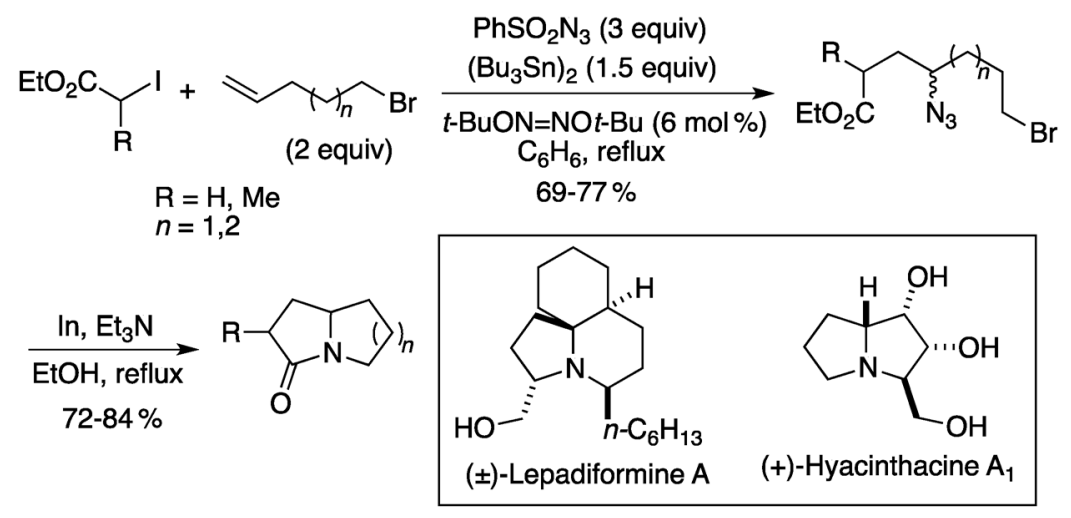

Scheme 2 Radical carboazidation and its application in synthesis.

Our recent efforts to address the limitation and expand the scope of the radical azidation and carboazidation are described here. For instance, radical carbozidation with $\alpha$-iodoketone, desulfitative carboazidation, and anti-Markovnikov hydroazidation of alkenes will be presented. The synthesis of several alkaloids achieved using the radical carboazidation as well as a unique intramolecular Schmidt reaction will be described.

\section{RADICAL CARBOAZIDATION OF $\alpha$-IODOKETONES}

In our first lepadiformine synthesis [16], the late-stage transformation of a lactam to the corresponding hydroxymethyl substituted pyrrolidine required five steps that included the addition of organometallic species and harsh reduction conditions. Recently, we reported a simple way to shorten this sequence by running the radical carboazidation with $\alpha$-iodoketones. This extension allows, after reduction, direct access to the desired substituted pyrrolidines (Scheme 3) [18]. It is possible, by the careful choice of the reaction partners, to install functionalized side chains having protected hydroxyl group and esters. 


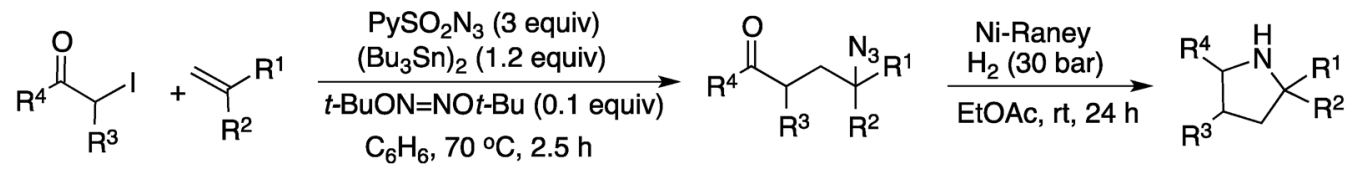<smiles>CC(=O)OCC(=O)CCC1([N])CCCCC1</smiles>

$88 \%$<smiles></smiles>

$69 \%$<smiles>COC(=O)CCC(=O)CCC1(C#N)CCCCC1</smiles>

$91 \%$<smiles>COC(=O)CCC1CCC2(CCCCC2)N1</smiles>

$95 \%$<smiles>CCOC(=O)CCC([N])CCC(=O)c1ccccc1</smiles>

$90 \%$

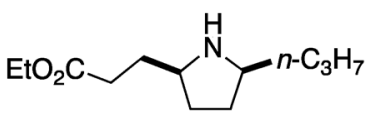

$99 \%$ (cis/trans $87: 13)$

Scheme 3 Radical carboazidation using $\alpha$-iodoketones.

\section{DESULFITATIVE CARBOAZIDATION}

Despite the fact that radical carboazidation is a very efficient process, the need for a 3 -fold excess of the arylsulfonyl azide and the use of organotin reagents limits its potential. While the triethylboranemediated reaction addressed the problem associated with the use of tin reagents [14], a more atom economical system that would reduce the amount of sulfonyl azide involved was highly desired. Zard and Kim used the $\alpha$-scission alkanesulfonyl radicals to develop an effective radical chain reaction [19-21]. Following the same principle, we envisioned that a single reagent could deliver the electrophilic ethoxycarbonylmethyl radical and act as the azidating agent for the $\mathrm{C}-\mathrm{N}$ bond formation [22]. The reaction with this reagent worked best when di-tert-butyldiazene $(t-\mathrm{BuN}=\mathrm{N} t-\mathrm{Bu})$, the alkene, and the sulfonyl azide are irradiated by light generated from a simple sun lamp. In general, the yields are superior to those obtained under the tin-mediated conditions (Scheme 4). The proposed mechanism is depicted in Scheme 5. Upon irradiation, $t$-BuN=N $t$-Bu decomposes to a tert-butyl radical which then adds to the sulfonyl azide. Fragmentation and $\mathrm{SO}_{2}$ elimination afford the carbon-centered electrophilic radical that reacts with the alkene. Finally, trapping of the resulting radical by the sulfonyl azide gives the alkyl azide and the starting sulfonyl radical that sustains the chain process.

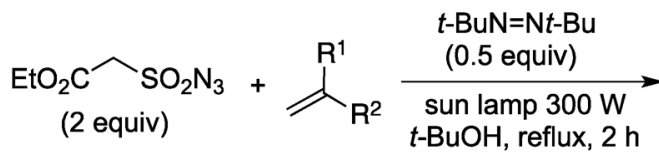<smiles>[R]C([R])(CCC(=O)OCC)NC</smiles><smiles>CCOC(=O)CCC1([N])CCCCC1</smiles>

$92 \%$ (ditin: $89 \%$ )<smiles>CCOC(=O)CCC(N)CCCBr</smiles>

$90 \%$ (ditin: $77 \%$ )<smiles>CCOC(=O)CCC([N])CSC</smiles>

$90 \%$ (ditin: $80 \%)^{*}$

* With EtOC(S) $\mathrm{SCH}_{2} \mathrm{CO}_{2} \mathrm{Et}$; decomposition with $\mathrm{ICH}_{2} \mathrm{CO}_{2} \mathrm{Et}$.

Scheme 4 The desulfitative carboazidation. 


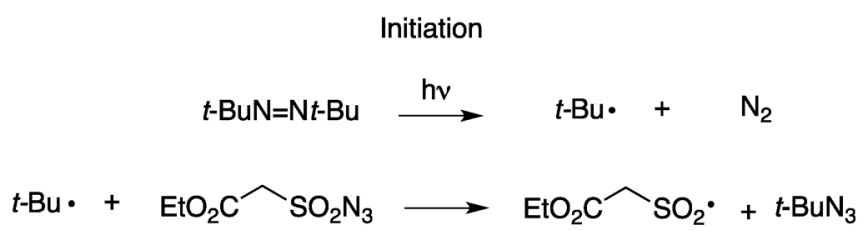

Propagation
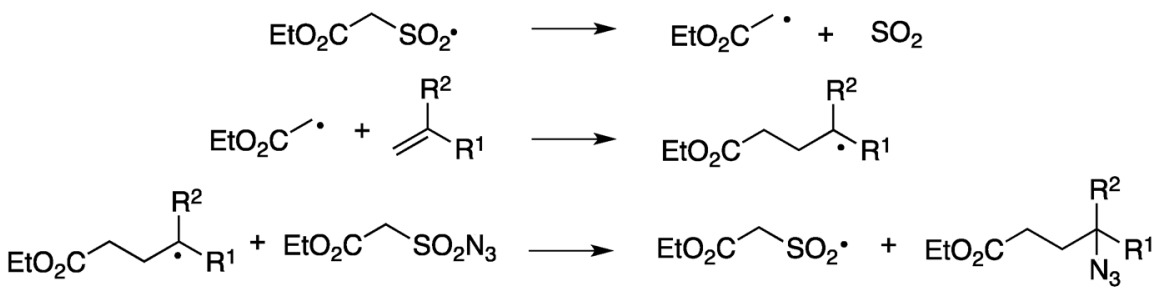

Scheme 5 Mechanism of the desulfitative carboazidation.

\section{ANTI-MARKOVNIKOV HYDROAZIDATION OF ALKENES}

The addition of hydrazoic acid to an alkene, notwithstanding its apparent simplicity, still remains a challenging transformation. A notable exception is the recent works of Carreira et al. who described the Markovnikov hydroazidation of alkenes using a cobalt catalyst and arenesulfonylazide [23-25]. In line with our recent reports that $B$-alkylcatecholboranes are useful radical precursors that participate in efficient chain reactions with arenesulfonyl radicals [26-32], we developed an efficient hydroboration/radical azidation sequence, hereby achieving a formal anti-Markovnikov addition of hydrazoic acid onto alkene (Scheme 6) [33]. The scope proved to be broad, and even styrene derivatives and terminal alkenes (primary radicals) could efficiently be hydroazidated in the reaction conditions. The radical nature of the process was further demonstrated via the cyclopropyl opening of (-)-carene and the 6-exo-

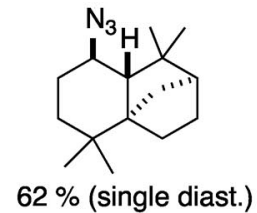<smiles>COc1ccc(C(C)C#N)cc1</smiles>

$77 \%$, $\left(\mathrm{PPh}_{3}\right)_{3} \mathrm{RhCl}$ as a catalyst (Markovnikov)

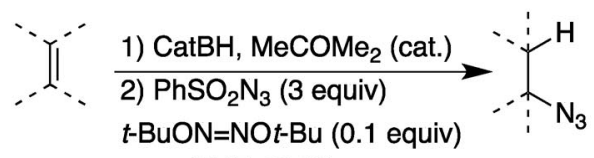
DMF, $80^{\circ} \mathrm{C}$

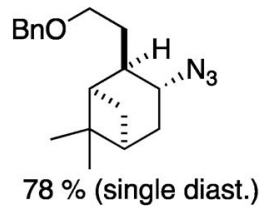<smiles>N#CC1CCC(c2ccccc2)CC1</smiles>

$67 \%(\mathrm{dr} 1.3: 1)$<smiles>CC(C)CCC(C)CCC([NH3+])C(C)(C)C</smiles>

$71 \%$

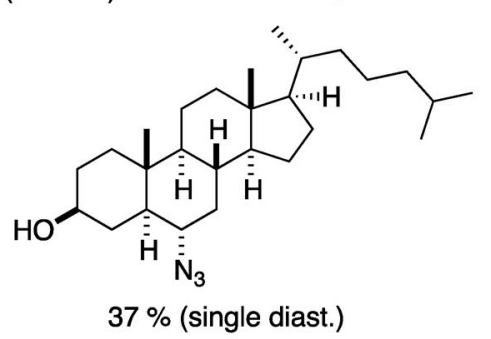

Scheme 6 Anti-Markovnikov hydroazidation. 
trig cyclization of $\beta$-citronellene (Scheme 7). The proposed mechanism is depicted in Scheme 8 . The reaction of tert-butoxyl radicals with the $B$-alkylcatecholborane initiates the reaction, generating the starting alkyl radical and a boronic ester. The alkyl radical then adds to the benzenesulfonyl azide to give the alkyl azide and a benzenesulfonyl radical that can propagate the chain by homolytic substitution with the $B$-alkylcatecholborane.

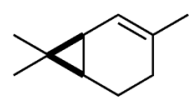

(-)-carene

\section{1) CatBH, $\mathrm{MeCOMe}_{2}$ (cat.) \\ 2) $\mathrm{PhSO}_{2} \mathrm{~N}_{3}$ (3 equiv) $t$-BuON=NOt-Bu (0.1 equiv)} $\mathrm{DMF}, 80^{\circ} \mathrm{C}$

$79 \%$

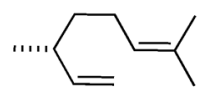

$\beta$-citronellene

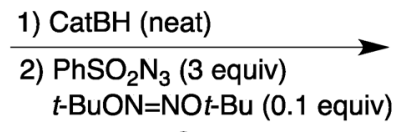

DMF, $80^{\circ} \mathrm{C}$

$45 \%$ (trans/cis $9: 1$ )<smiles>CC1C=CC(C(C)(C)N)CC1</smiles><smiles>CC1CCC(C(C)(C)N)CC1</smiles>

Scheme 7 Hydroazidation involving a radical rearrangement.

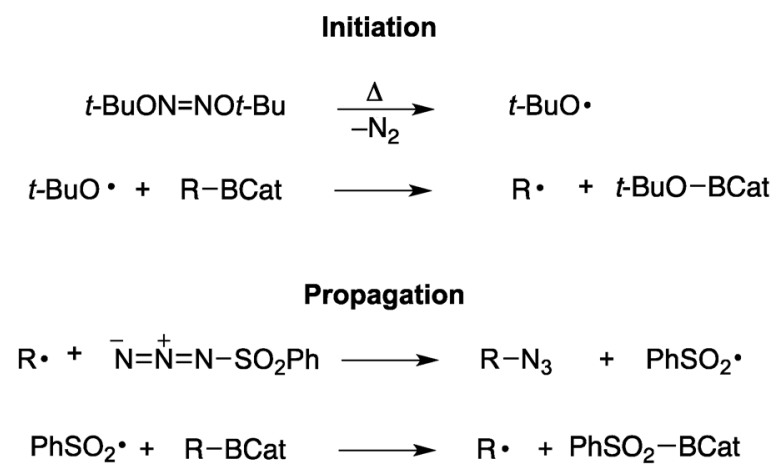

Scheme 8 Hydroazidation mechanism.

\section{RADICAL CARBOAZIDATION IN ALKALOIDS SYNTHESIS}

The radical carboazidation of unactivated alkenes allows one to prepare functionalized organic azides that, upon reduction or rearrangement, open the door to structural skeletons that are present in natural products. According to this strategy, (-)-indolizidine 167B, monomorine I, cylindricine C, and lepadiformine C (Fig. 1) have been recently prepared, and their synthesis will be briefly discussed here.
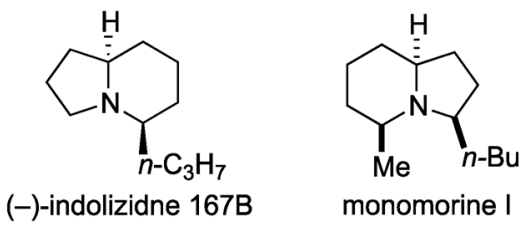

Fig. 1 Recently synthesized alkaloids.<smiles>CCCC[C@H]1CC(=O)[C@@H]2CCCC3C[C@@H](CO)N1[C@@H]32</smiles>

cylidrincine $\mathrm{C}$<smiles></smiles>

lepadiformine $\mathrm{C}$ 


\section{Synthesis of (-)-indolizidine 167B: Schmidt reaction under nonacidic conditions}

Indolizidine 167B is an alkaloid isolated from the Panamanian poison frog Dendrobates speciosus [34]. Despite its structural simplicity, this alkaloid has attracted the interest of the synthetic community and many total syntheses have been achieved [35,36].

A combination of the carboazidation and an intramolecular Schmidt rearrangement under nonacidic conditions gave access to (-)-indolizidine 167B as depicted in Scheme 9 [37]. The carboazidation on the optically active 2-substituted alkene afforded a mixture of diastereomeric azides, in which reduction of the ester to the alkyl chain and deprotection afforded the azidoalcohol in a 1:1 ratio of diastereoisomers. An intramolecular Schmidt rearrangement eliminated the stereochemically uncontrolled quaternary carbon center by generating a transient iminium ion. Selective reduction of the iminium ion from the less hindered face afforded (-)-indolizidine 167B in good yield as a single diastereoisomer.

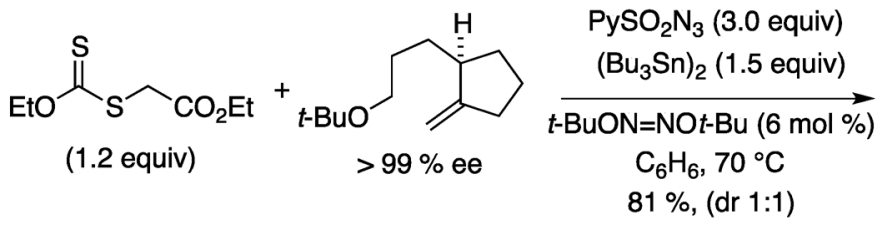<smiles>CCOCCCC1(N)CCCC1CCCOC(C)(C)C</smiles>
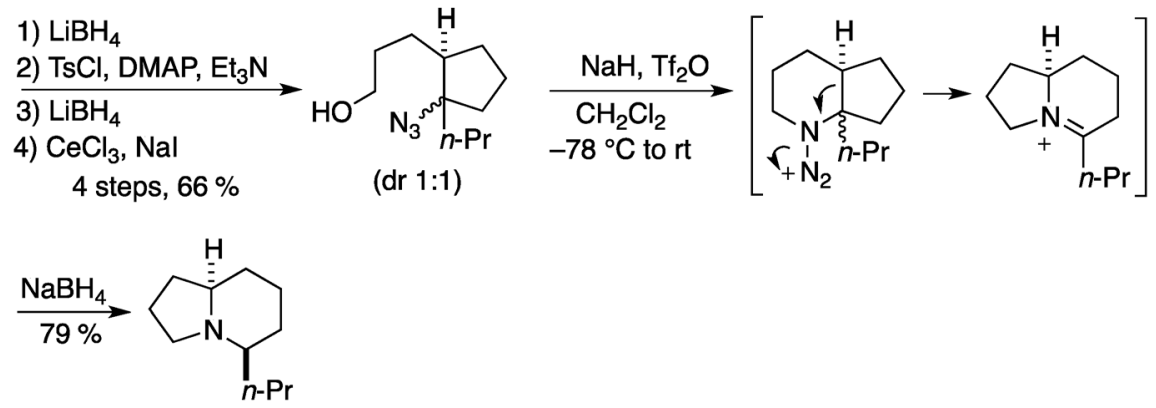

$(-)$-indolizidine 167B

(1 diastereomer)

Scheme 9 Synthesis of (-)-indolizidine 167B.

\section{Synthesis of monomorine I}

Monomorine I [38,39], isolated from two species of ants [40,41] and from the dendrobate Melanophryniscus stelzneri [42] was synthesized using the $\alpha$-iodoketone radical carboazidation (Scheme 10) [18]. The radical carboazidation between 2-iodohexan-2-one and hept-6-en-2-one proceeded in good yield, and bis-reductive amination of the azide afforded the natural product as a single diastereoisomer. The overall yield for the transformation of the iodoketone into monomorine I reached $57 \%$. 


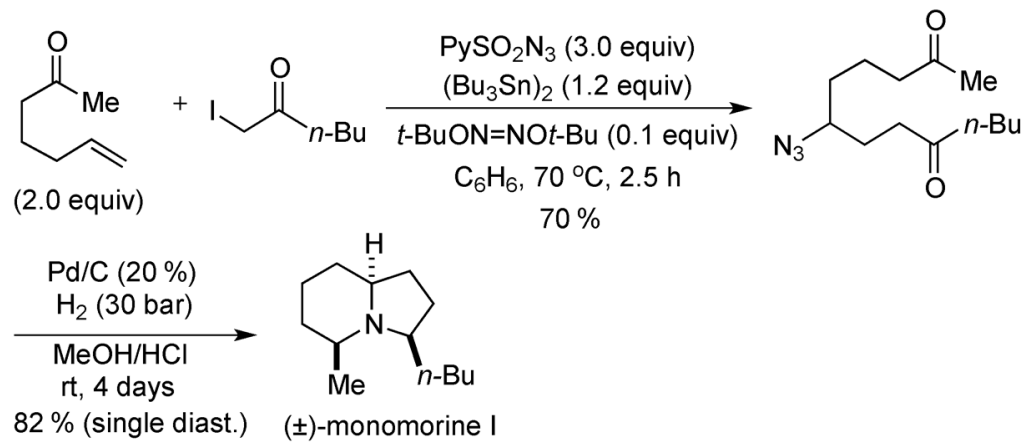

Scheme 10 Synthesis of monomorine I.

\section{Synthesis of cylindricine $C$ and its $C$-13 epimer}

Cylindricine C was isolated from the marine ascidian Clavelina cylindrica by Blackman et al. in 1994 [43]. Several total syntheses of cylindricine $C$ have been reported [44,45]. The generation of the quaternary amino-substituted center and the selective introduction of the hexyl side chain represent the main challenges for the synthesis of this target. These obstacles could be overcome using a $\alpha$-iodoketone-mediated radical carboazidation followed by a bis-reductive amination to assemble the pyrrolodecahydroquinoline structure [46]. The corresponding azide was obtained in $75 \%$ as a 7:3 ratio of diastereomers. The triethylborane-mediated conditions worked also, albeit in lower yield (59\%). While the reduced product was found to be epimeric at C-13, it was possible to obtain the 13-epicylindricine $\mathrm{C}$ and cylindricine $\mathrm{C}$ through an isomerization of the $\mathrm{C}-13$ center (Scheme 11).
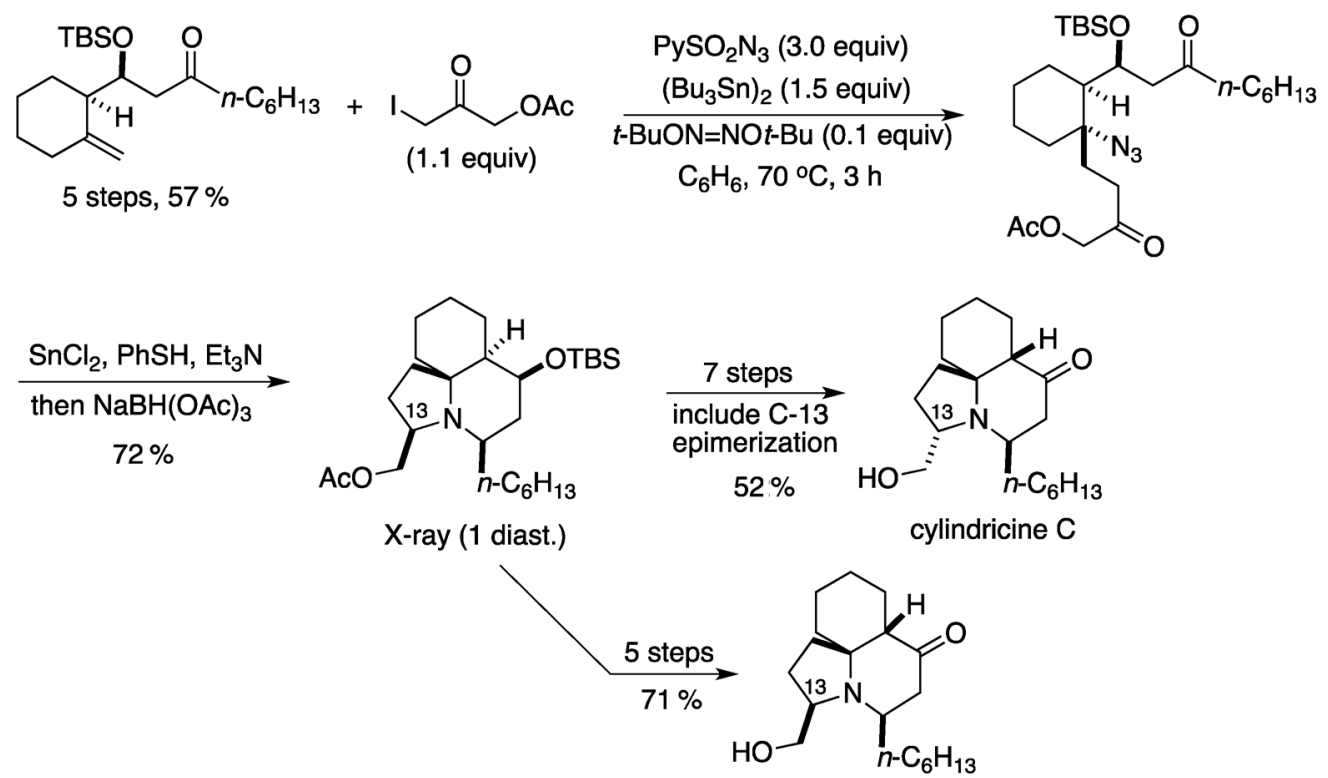

13-epicylindricine $\mathrm{C}$

Scheme 11 Synthesis of cylindricine C. 


\section{Formal synthesis of lepadiformine $C$}

Lepadiformine $\mathrm{C}$ was recently isolated from Clavelina moluccensis [47] and since then, two syntheses of the alkaloid have been accomplished [48,49]. In Aubé's synthesis [48], a lactam intermediate closely related to the one of our lepadiformine A intermediate [16] was prepared. As an illustration of the synthetic usefulness of the desulfitative carboazidation, we achieved a concise synthesis of Aubé's intermediate (Scheme 12) [22]. Starting from the 2-alkylated-methylenecyclohexane, the carboazidation afforded the azide in $82 \%$ as a 3:2 mixture of diastereomers. Reduction and lactamization directly gave Aubé's intermediate in $39 \%$.

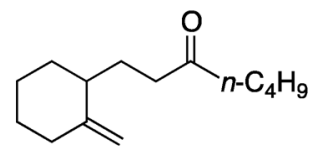

4 steps, $74 \%$<smiles>CCOCCOS(=O)(=O)OCc1ccccc1</smiles>

( 2 equiv)

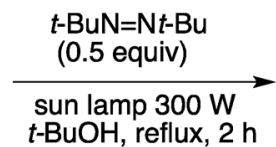

$82 \%$<smiles>CCOC(=O)CC[C@@H]1CCCCC1(N)CCC(=O)OCC</smiles>

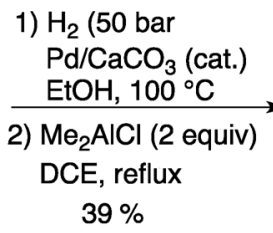

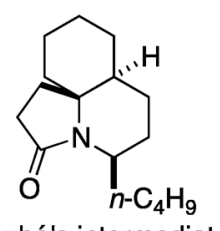

Aubé's intermediate
Ref. 48

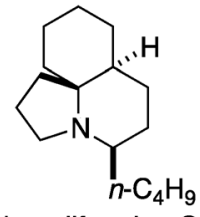

Scheme 12 Formal synthesis of lepadiformine C.

\section{CONCLUSION}

More than 10 years have passed since the discovery of the radical azidation reaction, and the following years have seen the simple azidation process being extended to intermolecular radical carboazidation. Recent progress in the field has allowed the development of novel alteration to the azidation, such as the use of $\alpha$-iodoketones and the desulfitative conditions in the carboazidation, up to the antiMarkovnikov hydroazidation. The potential of these reactions has been further demonstrated by the synthesis of several alkaloids.

\section{ACKNOWLEDGMENTS}

We are grateful to the Swiss National Science Foundation for financial support. We thank the BASF Corporation for the generous gift of organoboron reagents.

\section{REFERENCES}

1. P. Griess. Proc. R. Soc. London 13, 375 (1864).

2. P. Griess. Liebigs Ann. Chem. 137, 39 (1866).

3. S. Bräse, C. Gil, K. Knepper, V. Zimmermann. Angew. Chem., Int. Ed. 44, 5188 (2005).

4. S. Bräse, K. Banert (Eds.). Organic Azides: Syntheses and Applications, Wiley-VCH (2010).

5. T. M. V. D. Pinho e Melo. In Organic Azides: Syntheses and Applications, S. Bräse, K. Banert (Eds.), p. 53, Wiley-VCH (2010).

6. C. Jimeno, P. Renaud. In Organic Azides: Syntheses and Applications, S. Bräse, K. Banert (Eds.), p. 239, Wiley-VCH (2010).

7. C. Ollivier, P. Renaud. J. Am. Chem. Soc. 122, 6496 (2000). 
8. C. Ollivier, P. Renaud. J. Am. Chem. Soc. 123, 4717 (2001).

9. P. Panchaud, L. Chabaud, Y. Landais, C. Ollivier, P. Renaud, S. Zigmantas. Chem.-Eur. J. 10, 3606 (2004).

10. M. Minozzi, D. Nanni, P. Spagnolo. Chem.—Eur. J. 32, 7830 (2009).

11. D. Masterson, J. Shackleford. Synlett 1302 (2007).

12. P. Panchaud, C. Ollivier, P. Renaud, S. Zigmantas. J. Org. Chem. 69, 2755 (2004).

13. P. Renaud, C. Ollivier, P. Panchaud. Angew. Chem., Int. Ed. 41, 3460 (2002).

14. P. Panchaud, P. Renaud. J. Org. Chem 69, 3205 (2004).

15. P. Panchaud, P. Renaud. Adv. Synth. Catal. 346, 925 (2004).

16. P. Schar, P. Renaud. Org. Lett. 8, 1569 (2006).

17. L. Chabaud, Y. Landais, P. Renaud. Org. Lett. 7, 2587 (2005).

18. G. Lapointe, K. Schenk, P. Renaud. Chem.—Eur. J. 17, 3207 (2011).

19. B. Quiclet-Sire, S. Z. Zard. J. Am. Chem. Soc. 118, 1209 (1996).

20. F. Bertrand, F. Le Guyader, L. Liguori, G. Ouvry, B. Quiclet-Sire, S. Seguin, S. Z. Zard. C. R. Acad. Sci., Ser. IIC 4, 547 (2001).

21. S. Kim, S. Kim. Bull. Chem. Soc. Jpn. 80, 809 (2007).

22. K. Weidner, A. Giroult, P. Panchaud, P. Renaud. J. Am. Chem. Soc. 132, 17511 (2010).

23. J. Waser, H. Nambu, E. M. Carreira. J. Am. Chem. Soc. 127, 8294 (2005).

24. J. Waser, B. Gaspar, H. Nambu, E. M. Carreira. J. Am. Chem. Soc. 128, 11693 (2006).

25. B. Gaspar, J. Waser, E. M. Carreira. Synthesis 3839 (2007).

26. P. Renaud, A. Beauseigneur, A. Brecht-Forster, B. Becattini, V. Darmency, S. Kandhasamy, F. Montermini, C. Ollivier, P. Panchaud, D. Pozzi, E. M. Scanlan, A.-P. Schaffner, V. Weber. Pure Appl. Chem. 79, 223 (2007).

27. C. Ollivier, P. Renaud. Angew. Chem., Int. Ed. 39, 925 (2000).

28. C. Ollivier, P. Renaud. Chem.-Eur. J. 5, 1468 (1999).

29. A.-P. Schaffner, P. Renaud. Eur. J. Org. Chem. 2291 (2004).

30. A.-P. Schaffner, P. Renaud. Angew. Chem., Int. Ed. 42, 2658 (2003).

31. A.-P. Schaffner, B. Becattini, C. Ollivier, V. Weber, P. Renaud. Synthesis 2740 (2003).

32. A.-P. Schaffner, V. Darmency, P. Renaud. Angew. Chem., Int. Ed. 45, 5847 (2006).

33. A. Kapat, A. König, F. Montermini, P. Renaud. J. Am. Chem. Soc. 133, 13890 (2011).

34. M. W. Edwards, J. W. Daly, C. W. Myers. J. Nat. Prod. 51, 1188 (1988).

35. L. Hui, S. Deyong, C. Guolin, X. Jimin, W. Xinyan, H. Yuefei. Org. Biomol. Chem. 8, 1899 (2010).

36. D. Stead, P. O'Brien, A. Sanderson. Org. Lett. 10, 1409 (2008).

37. A. Kapat, E. Nyfeler, G. T. Giuffredi, P. Renaud. J. Am. Chem. Soc. 131, 17746 (2009).

38. V. B. Reddy Iska, V. Vendolino, O. Wiest, P. Helquist. J. Org. Chem. 75, 1325 (2010).

39. Y.-G. Wang, T. Kumano, T. Kano, K. Maruoka. Org. Lett. 11, 2027 (2009).

40. T. H. Jones, H. L. Voegtle, H. M. Miras, R. G. Weatherford, T. F. Spande, H. F. Garraffo, J. W. Daly, D. W. Davidson, R. R. Snelling. J. Nat. Prod. 70, 587 (2007).

41. F. J. Ritter, I. E. M. Rotgans, E. Talman, P. E. J. Verweil, F. Stein. Experientia 29, 530 (1973).

42. H. M. Garraffo, T. F. Spande, J. W. Daly, A. Baldessari, E. G. Gros. J. Nat. Prod. 56, 357 (1993).

43. C. Li, A. J. Blackman. Aust. J. Chem. 47, 1355 (1994).

44. T. J. Donohoe, P. M. Brian, G. C. Hargaden, T. J. C. O'Riordan. Tetrahedron 66, 6411 (2010).

45. A. C. Flick, M. J. A. Caballero, A. Padwa. Tetrahedron 66, 3643 (2010).

46. G. Lapointe, K. Schenk, P. Renaud. Org. Lett. 13, 4774 (2011).

47. M.-P. Sauviat, J. Vercauteren, N. Grimaud, M. Juge, M. Nabil, J.-Y. Petit, J.-F. Biard. J. Nat. Prod. 69, 558 (2006).

48. A. M. Meyer, C. E. Katz, S.-W. Li, D. Vander Velde, J. Aubé. Org. Lett. 12, 1244 (2010).

49. M. A. Perry, M. D. Morin, B. W. Slafer, S. A. Wolckenhauser, S. D. Rychnovsky. J. Am. Chem. Soc. 132, 9591 (2010). 